\title{
Do conhecimento a prática: inserção da História da Ciência no Mestrado em Ensino de Física
}

\author{
Cassiana Barreto Hygino Machado \\ Tiago Destéffani Admiral \\ Renata Lacerda Caldas
}

\section{Resumo}

Neste trabalho é apresentada uma proposta para a inserção da história da ciência e de aspetos da natureza da ciência no ensino de física, em uma disciplina obrigatória do Mestrado Nacional Profissional em Ensino de Física (MNPEF). Durante o desenvolvimento da disciplina foi discutido com os discentes sobre filosofia, história e natureza da ciência no ensino, além disso, os discentes deveriam elaborar sequências didáticas embasadas no método de estudo de caso. O estudo de caso deveria ser histórico e seguir as orientações para este tido de caso. Estas sequências didáticas deveriam levar em consideração os três eixos da alfabetização científica: aprendizagem de conceitos científicos, compreensão da natureza das ciências e entendimento das relações entre ciência, tecnologia, sociedade e ambiente. Mediante a análise dos estudos de caso construídos pode-se perceber que estes foram elaborados de acordo com as orientações estabelecidas. A análise das sequências didáticas propostas pelos discentes, mostrou que houve maior preocupação com o ensino de conceitos científicos. A natureza da ciência foi mais explorada a partir do caso histórico e tiveram dificuldades em discutir aspectos relacionados as implicações da ciência, tecnologia, sociedade e ambiente.

Palavras chave: História da Ciência, Sequência Didática, Natureza da Ciência 


\title{
From knowledge to practice: Insertion of the History of Science in the Master's Degree in Physics Teaching
}

\author{
Cassiana Barreto Hygino Machado \\ Tiago Destéffani Admiral \\ Renata Lacerda Caldas
}

\begin{abstract}
This paper presents a proposal for the insertion of the history of science and aspects of then ature of science in physics teaching, in a compulsory discipline of the National Professional Masters in Physics Teaching (MNPEF). During the development of the discipline was discussed with the students about philosophy, history and nature of science in teaching, in addition, students should develop didactic sequences based on the case study method. The case study should be histori caland follow the guidelines for this case. These didactic sequences should take into account the three axes of scientific literacy: learning scientific concepts, understanding the nature of sciences and understanding the relationships between science, technology, society and the environment. Through the analysis of the case studies constructed it can be seen that these were well elaborated. The nalysis of didactic sequences proposed by the students showed that there was greater concern with the teaching of scientific concepts. The nature of science was more explored from the historical case and had difficulties in discussing aspects related to the implications of science, technology, society and environment.
\end{abstract}

Keywords: Historyof Science, DidacticSequence, Natureof Science 


\section{Introdução}

É notório perceber que o ensino de ciências, em especial o ensino de física, não tem despertado tanto o interesse dos estudantes, acarretando maiores dificuldades no seu aprendizado. Segundo Pozo e Crespo (2009),

[..] não há dúvida de que boa parte delas é consequência das próprias práticas escolares de solução de problemas, que tendem a estar mais centradas em tarefas rotineiras ou delimitadas, com escasso significado científico ("qual será a velocidade alcançada aos 43 segundos por um projétil que, partindo do repouso, está submetido a uma aceleração constante de $2 \mathrm{~m} / \mathrm{s}^{2}$ ?"), do que em verdadeiros problemas com conteúdo científico ("por que os dias são mais longos no verão do que no inverno?”) (POZO; CRESPO, 2009, p.17).

A ciência, especialmente a física, por muitas vezes, é apresentada como um conjunto de conhecimentos prontos e acabados, sem fazer referência as influências ideológicas, políticas, econômicas e sociais, que nortearam os cientistas em suas pesquisas e contribuições. Além de apresentar visões de que a ciência possui um único método infalível, ou de que é feita por grandes gênios (MOURA, 2014).

No entanto, o professor atento pode ser capaz de melhorar esse cenário, refletindo e mudando a própria prática. Isto pode ser conseguido a partir de um trabalho contextualizado, incluindo nas aulas a discussão de aspectos inerentes ao processo de desenvolvimento da ciência. Além disso, a utilização de metodologias ativas de ensino em sua aula, pode ser um caminho para organizar as aulas de modo a colocar o aluno com um sujeito ativo (BERBEL, 2011).

Na busca de meios para se contextualizar o ensino e mostrar o processo de transformação da ciência, e em especial da Física, a História e a Filosofia da Ciência (HFC), têm sido indicadas como uma estratégia didática que pode trazer benefícios em vários níveis. A pesquisa nesse sentido é ampla, contando com uma vasta bibliografia, tanto nacional quanto internacional (VILLANI, PACCA e FREITAS, 2009; FORATO, 2009)

A utilização de uma abordagem histórica em aulas de ciências, de acordo com estudos realizados por Mendes e Batista (2016), também facilita a quebra do excesso de matematização atribuído ao ensino, em especial de física, que, de acordo com as autoras, por muitas vezes obscurece o conhecimento de forma mais ampla, o reduzindo à um conjunto de algoritmos matemáticos sem significado. Nesse sentido essa abordagem histórica também pode contribuir para a alfabetização científica, uma vez que possibilita uma discussão mais ampla dos conceitos trabalhados em aula.

Pensando nestes dois vieses, a incorporação da HFC no ensino e a adoção de metodologias ativas no ensino, foi estruturada uma disciplina do MNPEF, com o propósito de proporcionar aos discentes, professores atuantes na rede pública e particular, essa percepção ISSN 2526-2882 
da necessidade de ensinar física de uma forma mais contextualizada, colocando o aluno como sujeito ativoe de ter num novo olhar sobre o desenvolvimento do conhecimento científico.

Durante todo o desenvolvimento da disciplina buscou-se investigar: de que maneira a apresentação da discussão sobre a história e natureza da ciência influenciaria as representações de ciência dos discentes ao final da disciplina, de modo a contribuir com posturas mais ativas dos estudantes?

\title{
Referencial teórico
}

A literatura mostra que a utilização da HFC no ensino pode contribuir com ummelhor aprendizado de conceitos científicos, tornar as aulas mais interessantes, desafiadoras e reflexivas (MATTHEWS, 1995).

As pesquisas apontam que uma abordagem histórica no ensino de ciências permite aos estudantes adquirirem um melhor conhecimento sobre a natureza da ciência, o que, conforme as concepções consideradas mais adequadas atualmente, permite a formação de um cidadão crítico, apto, inclusive, para a tomada de decisões tecno-científicas (ACEVEDO et. al., 2005; PRAIA, GIL-PEREZ e VILCHES, 2007). Segundo Moura:

\begin{abstract}
A natureza da Ciência é entendida como um conjunto de elementos que tratam da construção, estabelecimento e organização do conhecimento científico. Isto pode abranger desde questões internas, tais como método científico e relação entre experimento e teoria, até outras externas, como a influência de elementos sociais, culturais, religiosos e políticos na aceitação ou rejeição de ideias científicas. A compreensão da natureza da Ciência é considerada um dos preceitos fundamentais para a formação de alunos e professores mais críticos e integrados com o mundo e a realidade em que vivem. Moura, 2014).
\end{abstract}

Nesse sentido, a partir da análise de documentos em vários países, foram categorizados diversos aspectos relevantes e desejáveis no ensino da história da ciência, esses são conhecidos como aspectos consensuais (MCCOMAS; ALMAZROA; CLOUGH, 1998, p. 513). Tais aspectos se referem à abordagens que auxiliam ao aluno a compreender de maneira mais adequada a natureza do conhecimento científico, entre os aspectos consensuais está, por exemplo, considerar que a ciência é uma atividade de cooperação.

Esses aspectos consensuais são norteadores do discurso e prática que devem ajudar, tanto o professor quanto o aluno, a superar o que Perez et. al. (2001) classifica como visão deformada da ciência. Em seu estudo os autores perceberam que existe uma tendência de reprodução de certos estereótipos sobre o conhecimento científico, visões distorcidas e que influenciam não apenas a forma de ensinar ciências, mas também na forma com a qual os alunos se relacionam com ela. Entre as diversas visões deformadas da ciência está, por exemplo, a visão elitista de ciência, que reproduz a ideia de que apenas certos escolhidos 
geniais "descobrem" o conhecimento, sem que haja colaboração, contradições ou intervenções externas.

Uma maneira de auxiliar o professor utilizar a abordagem de HFC, e romper com esses tipos de visão deformada, pode ser com o uso de:fontes originais, estudos de caso, dramatização, experimentos históricos e biografiae autobiografias de cientistas (MCCOMAS, 2013).

O método de estudo de caso se utiliza de narrativas sobre indivíduos enfrentando decisões ou dilemas (HERREID, 1994). Este método é baseado no método deAprendizado Baseado em Problemase visainserir os discentes nocontexto real de sua área de estudo, frente aos problemas existentes, a fimde instigar o pensamento ativo e crítico e estimular a capacidade de tomadas de decisões (SÁ \&QUEIROZ, 2009).

A aproximação dos estudos de caso à história da ciência se deve, à capacidade dos estudos de caso proporcionarema compreensão de fatos, valores e contextos presentes em sua narrativa, que pode ser uma narrativa histórica, impregnada de conflitos e questionamentos de uma época.

Para a construção de um estudo de casohistórico toma-secomo base as orientações de Stinner et al. (2003, p.620), que sugerem uma estruturação em trêspartes: i) contexto histórico: apresenta as ideias científicas do período histórico e mostra como esse período está conectado ao tema de estudo.ii) experimento(s) e ideias principais:traz um relato das experiências de um personagem da história da Ciência. iii) implicações para a alfabetização científica e o ensino de ciências.

Segundo Sasseron et al (2013) o entendimento, da natureza da ciência, dos conceitos científicos e das relações de tais conceitos com o contexto tecnológico e social, são eixos estruturantes para a alfabetização científica.

\section{Metodologia}

O presente trabalho foi desenvolvido na disciplina obrigatória: "Marcos do desenvolvimento de Física” no pólo do MNPEF em uma Instituição Federal de ensino do estado do Rio de Janeiro.

O MNPEF é um programa nacional de pós-graduação de caráter profissional, voltado a professores de ensino médio e fundamental com ênfase na área de física e tem como objetivo o domínio de conteúdos de física e de estratégias atuais de ensino para aperfeiçoamento docente e aplicação em sala de aula.

A disciplina é realizada de forma intensiva, ou seja, durante uma semana, em turno integral, manhã e tarde e durante o período de férias, visto que os discentes são professores da rede pública e particular, portanto necessitam de um calendário flexibilizado. 
Para o desenvolvimento de trabalho, a disciplina foi dividida em duas partes: uma parte teórica relacionada aos estudos de filosofia, história e natureza da ciência no ensino e outra parte prática, na qual os discentes realizaram diferentes atividades.

O presente trabalho foi realizado no ano de 2019, com uma turma de 10 alunos. Todos os alunos são professores atuantes em instituições de ensino públicas e privadas. A estrutura da disciplina é mostradano Quadro 1. Cada aula corresponde a um dia integral, ou seja, manhã e tarde.

Quadro 1: Estrutura da disciplina Marcos do desenvolvimento da física

\begin{tabular}{|c|c|}
\hline Parte Teórica & Parte Prática \\
\hline $\begin{array}{l}\text { Apresentação: Filosofia da Ciência sob a } \\
\text { perspectiva de Tomas Khun (Aula 1) }\end{array}$ & $\begin{array}{l}\text { Cada discente deveria escolher um paradigma } \\
\text { proposto por Khun, discutir e apresentar uma } \\
\text { proposta de aula. }\end{array}$ \\
\hline $\begin{array}{l}\text { Apresentação: Natureza da ciência e Visões } \\
\text { adequadas e deformadas sobre } \quad \text { o } \\
\text { conhecimento científico (Aula 2) }\end{array}$ & $\begin{array}{l}\text { Três grupos } \\
\text { 1- Identificar nos episódios históricos (Alexandre } \\
\text { Volta, Galvani, Galileu, Appert e Foucault) as visões } \\
\text { de ciência presentes e como trabalhar em sala de } \\
\text { aula. } \\
\text { 2- Identificar em livros didáticos qual a visão de } \\
\text { ciência presente. (Estes livros são utilizados pelos } \\
\text { discentes em suas escolas). }\end{array}$ \\
\hline $\begin{array}{l}\text { Apresentação: História da Ciência no } \\
\text { Ensino de Física } \\
\text { Como tem sido utilizada no Encontro } \\
\text { Nacional de Pesquisa em Ensino de Física } \\
\text { (EPEF) e no Encontro Nacional de Pesquisa } \\
\text { em Educação em Ciências (ENPEC) } \\
\text { O uso de estudos de caso históricos } \\
\text { Exemplos de Casos históricos (Aula 3) }\end{array}$ & $\begin{array}{l}\text { Três grupos } \\
\text { Construção de Casos históricos (episódio de Física } \\
\text { Moderna e Contemporânea escolhido pelos } \\
\text { discentes) }\end{array}$ \\
\hline $\begin{array}{l}\text { Apresentação: Sequência didática } \\
3 \text { passos (Linhares e Reis, 2008) } \\
3 \text { Momentos pedagógicos (Delizoicov e } \\
\text { Angotti, 1990) (Aula 4) }\end{array}$ & $\begin{array}{l}\text { Construção de Sequências didáticas com os estudos } \\
\text { de caso históricos. } \\
\text { Apresentação dos casos e Sequências }\end{array}$ \\
\hline (Aula 5) & $\begin{array}{l}\text { Apresentação de trabalhos sobre filosofia da ciência } \\
\left(1^{\circ} \text { dia }\right) \text {. }\end{array}$ \\
\hline
\end{tabular}
Fonte: Produção própria

No presente trabalho, serão analisados os casos e sequências construídos pelos discentes, deste modo, por questão de espaço, esta parte será detalhada.

Durante os trabalhos realizados na disciplina, os discentes foram divididos em três grupos. Cada grupo escolheu um episódio da física moderna e contemporânea e elaborou o estudo de caso histórico e uma sequência didática, o estudo de caso históricodeveria seguir a estrutura sugerida por Stinner et al (2003).

Além disso, a sequência didática elaborada poderia seguir duas organizações, uma delasseguindo as orientações de Linhares e Reis (2008, p. 561). Passo 1: realiza-se a leitura do estudo de caso e os estudantes devem elaborar soluções acerca do problema proposto, dessa 
forma as ideias inicias dos alunos ficam evidenciadas. Passo 2: o professor apresenta os conteúdos propostos e necessários para os alunos responderem o problema. Podem ser realizadas uma ou várias atividades. Passo 3: o problema deve ser retomado e agora incorporando os conhecimentos adquiridos ao longo do passo 2.

A outra alternativa de organização da sequência poderia ser os três momentos pedagógicos. Proposta por Delizoicov e Angotti (1990), a proposta de organização por momentos pedagógicos passa por três partes distintas. Problematização: Etapa na qual se apresentam as situações para promover a discussão inicial com os alunos, essa etapa se deve relacionar a situação problema cotidiana com os conhecimentos científicos a serem abordados. Os autores indicam ainda que o professor deve se manter como mediador das discussões e fomentá-las, e não fornecer quaisquer tipos de respostas prontas nessa etapa.

Organização do Conhecimento: Nessa etapa os conhecimentos específicos de ciências, que são necessários para a compreensão de uma solução para a situação proposta, devem ser trabalhados em sala com os alunos, é nesse momento que os conceitos científicos devem ser incluídos na discussão inicial. Isso deve ser feito por meio de atividades diversificadas, com a finalidade de trabalhar aspectos diferentes do mesmo conceito.

Aplicação do conhecimento: Esse último momento pedagógico deve ser o espaço no qual o professor auxilia o aluno a estabelecer uma conexão entre os conceitos e fenômenos apresentados e sua relação com a situação problema em si. Esse é o momento no qual os alunos devem perceber a aplicação direta dos conhecimentos abordados em sala com os temas cotidianos apresentados inicialmente, o professor, que continua agindo como mediador, deve se encarregar de levantar questões pendentes sobre a aprendizagem quando forem verificadas, e reforçar conceitos desejáveis.

\section{Discussão dos resultados}

Os 10 discentes foram divididos em três grupos, o primeiro grupo selecionou o episódio sobre a radiação de corpo negro, o segundo grupo escolheu o episódio sobre o efeito fotoelétrico, enquanto o terceiro grupo escolheu o episódio sobre a natureza dual da luz. As figuras 1, 2 e 3, são os textos produzidos pelos três grupos de discentes para o estudo de caso histórico, e em seguida, são realizadas suas análises.

Figura 1: Texto de estudo de caso sobre radiação de corpo negro.

ISSN 2526-2882

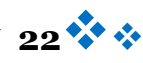




\section{A radiação do "corpo negro"}

No perío do da revoluçãoindustrial na Alemanha, houve uma grande necessidade da melhoria na eficiência das usinas de carvão e do controle de temperatura para a produção de aço de melhor qualidade. A utilização de temômetros comuns foi descartada devido à magnitude de tais temperaturas. Alguns cientistas acreditavam que alguns corpos poderiam absorver toda a radiação incidida sobre eles, esses corpos seriam chamados de "Corpo Negro". Após vános experimentos feitos por eles, perceberam que a ra điaçãotérmica emitida pelos corpos, na natureza, terá uma parte refletida e outra que será absorvida. Como nanaturezanada é perfeito, a existência dessetipo de corpo ainda não foi comprovada. No inicio do século XX Max Planck fez diversos estudos sobre o corponegro, ele foi capaz de descrever a intensidade da radiação emitida como uma função de comprimento de onda. Para contomar a dificuldade começarama estudar as temperaturas através do espectro, por meio das cores emitidas proverientes dos fomos em diferentes temperaturas. A partir da análise das luzes, utilizando prismas ópticos medindo a intensidade das partes do espectro, foram obtidas curvas experimentais. Entretanto, a ra diação emitida mostrou uma falhana teonia clássica, a teoria só funcionava para baixas temperaturas, para altas temperaturas havia uma falha nas medições e na curva, ficou conhecida como "Catástrofe do Ultravioleta", eles precisavam das medições a altas temperaturas. Planck solucionou o problema daradiação do corpo negro. Um corpo só poderia emitir números inteiros de quanta energético, análogo a uma escada, você só pode subirum degrauinteiro, vocênão sobe meio degrau Pensando sobre essa situação, emuma aula de física uma professora resolve fazer umbolo e explicar fenômenos relacionados à temperatura e pressão e um dos alunos notou que dentro do formo, uma das grades apresentava uma coloração avermelhada, sendo que ela era preta, muito se discutiu, entretanto os alunos não conseguiam chegar a uma conclusão. Utilizando seus conhecimentos em Física, quais fatores podem ter influenciado a mudança de coloração da grade do forno? Considerando um corpo negro, o mesmo poderia apresentar outra coloração? Poderia ser possível o ser humano se tornar um corpo negro? Como os cientistas sabem a temperatura das estrelas? Qual cor de camiseta, você prefere usar no verão, preta ou branca?Por que? Por que o radiador da geladeira é da cor preta? 0 que é um corpo negro? 0 que ocorreu com a ciência do período anterior à catástrofe do ultravioleta?Qual fato social levou a essa descoberta?

Fonte: Produção própria

Figura 2: Texto do estudo de caso sobre efeito fotoelétrico.

\section{DO DESAFIO A MODERNIDADE: O CAMINHO DO EFEITO FOTOELÉTRICO}

No meado do século XIX, a Academia de Ciências de Berlim lançou um desafio premiando quem conseguisse a verificação experimental das teorias de James Clerk Maxxel. O fisico alemão Heinrch Rudolph Hertz que sempre gostou de atividades experimentais aceitou o desafio proposto e assim começou a estudar os fenômenos luminosos através de experimentos. Fazendo um trabalho intensivo com a produção de descargas elétricas com duas placas de metais (faiscas), conseguiu manipular de maneira efetiva a criação de faíscas analisando o seu comportamento em diversos meios. Dessa forma, Hertz consegue resolve o problema proposto pela Academia de Ciências de Berlim.

No decorrer da sua pesquisa percebeu uma relação entre os efeitos elétricos com os efeitos esperados pela luz, a firmando que era altamente provável a hipótese da luz ser um fenômeno elétrico. Sendo assim, continuou os experimentos que envolviam a luz e a eletricidade mesmo após ter vencido o desafí.

Como ressaltado, o experimento muito estuda do por Hertz era o de produzir descargas elétricas e durante o curso dessa investigação, um fenômeno o chamou a atenção, ele percebeu um problema: uma faísca primária influenciava o comportamento da faísca secundána. Essa observação o levou ao aprofundamento dessa questão, e assim chegou a conclusão que a influencia no comportamento da segunda faísca era causa do pela luz da primeira faísca, mas Hertz não se preocupou naquele momento em investigar com maior profundidade a teoria desse fenômeno. Assim, podemos notar que Hertz percebeu algo incomum acontecendo, mas não conseguiu explica-lo.

Algum tempo depois, o fisico Von Lenard, baseado nas observações de Hertz, fez um outro experimento com placas de diferentes metais colocados dentro de ampolas de vidro e assim identificou que a luz incidente conseguia arrancar elétrons de algumas superficies metálicas, as observações desse experimento levaram a um questionamento: Por que a luz conseguia ejetar elétrons de alguns metais?

Foi nesse contexto que novas ideias surgiram para solucionar o questionamento, como os conceitos de pacote de energia de Max Planck e as contribuições de Albert Einstein que afimou que a luz seria formada por corpúsculos com uma determinada energia fixa chamada fótons que conseguia penetrar em uma superfície metálica e ejetar um elétron da superficie, fenômeno que ficou conhecido como Efeito Fotoelétrico.

Desta maneira surge a história do efeito fotoelétrico que nos dias atuais apresentam diversas aplicações como: as portas automáticas vistas em shoppings, em postes de iluminação pública e em células fotoelétricas.

Com base no texto apresentado, você deve refletir e descrever o que levou Hertz a não conseguiu explicar o fenômeno que o chamou atenção em seu experimento. Em relação ao efeito, você saberia explicar o processo pelo qual o fóton consegue ejetar o elétron do metal? Além das aplicações citadas acima você conhece alguma outra aplicação? Das aplicações citadas explique o processo de funcionamento de uma delas. Seria você capaz de inventar uma ablicacão dara 0 efeito fotoelétrico?

Fonte: Produção própria 
Figura 3: Texto do estudo de caso sobre a luz.

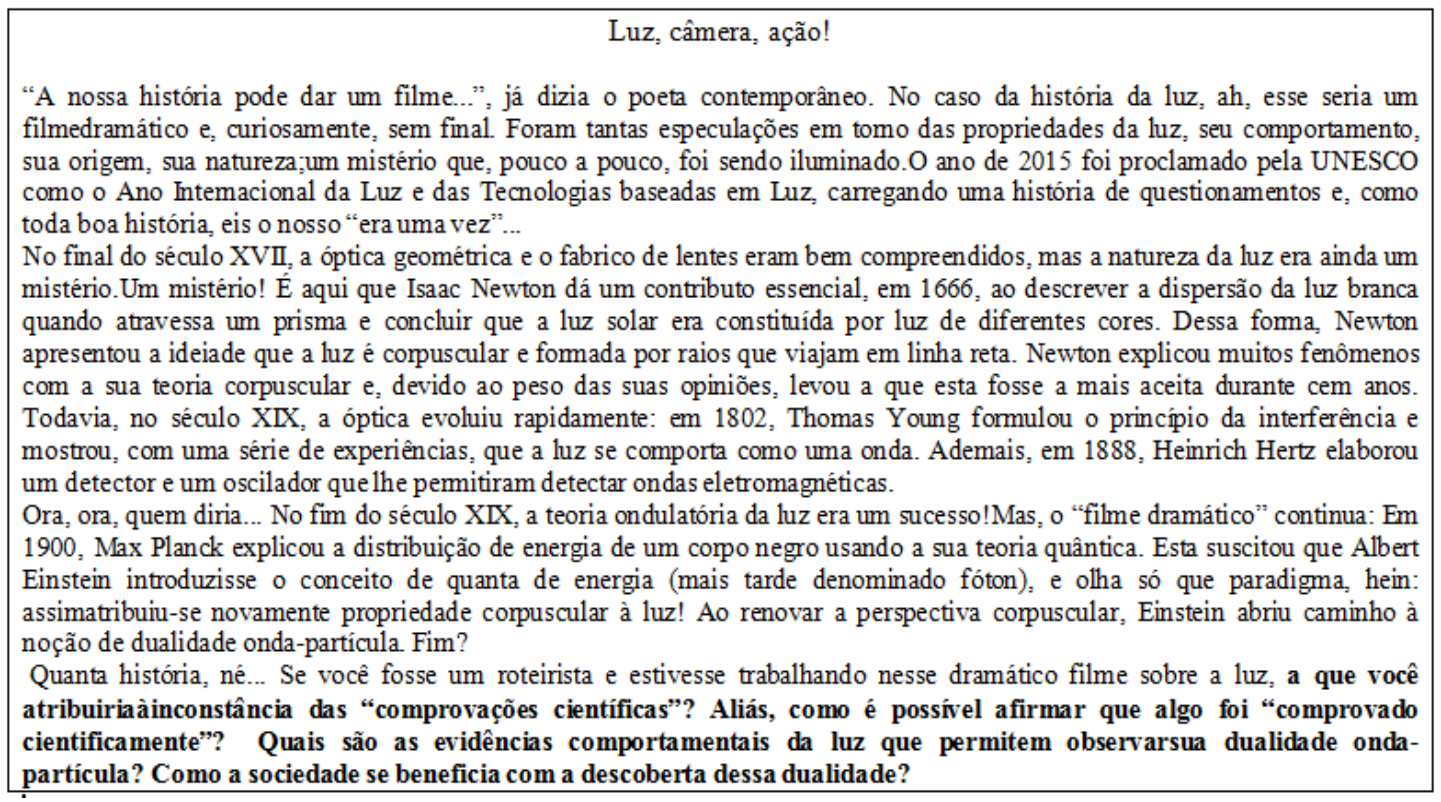

Fonte: Produção própria

Ao realizar a análise dos estudos de caso históricos elaborados pelos discentes, tomase como base as orientações de Stinner et al(2003), supracitadas.

No que se refere a primeira orientação: Contexto Histórico, percebe-se que no caso "A radiação do corpo negro” este é feito de forma adequada, pois traz o cenário da época, relacionando aos aspectos sociais e econômicos envolvidos. No segundo caso "Do desafio a modernidade: o caminho do efeito fotoelétrico", percebe-se que o contexto histórico da época foi explorado de uma forma muito rápida, não permitindo aos estudantes o entendimento do motivo pelo qual a academia lançou aquele desafio, quais os problemas eram enfrentados a época. No terceiro caso "luz, câmera, ação", é dado um formato um pouco diferenciado a narrativa, com toques interessantes e criativos, o que pode chamar mais ainda a atenção do aluno. No que se refere ao contexto histórico, este é explicado ao longo o caso, entretanto, não são mencionadas questões e o cenário por trás destas ideias.

No que se refere a segunda orientação: Experimentos e ideias principais, percebe-se no caso “A Radiação do corpo negro" que faltaram alguns detalhes sobre o experimento realizado. Questões importantes relacionadas ao assunto poderiam ter sido abordadas, como, por exemplo, a determinação da constante de Planck, discussões sobre a relação da temperatura de um corpo e sua faixa de emissão e também fenômenos que envolvem corpos na temperatura do zero absoluto.No entanto, as ideias presentes na época foram exploradas com riquezas de detalhes.

Já no segundo caso, relacionado ao efeito fotoelétrico, o experimento é tratado com mais detalhes, assim como as ideias e teorias que surgiram sobre o fenômeno observado. Isso 
demonstrou uma preocupação maior do grupo no que diz respeito aos conceitos, em detrimento do contexto histórico. No terceiro caso, a respeito da natureza da luz, as ideias e experimentos realizados são tratados, de forma a facilitar o entendimento do aluno sobre o assunto. Sobre esse aspecto podemos evidenciar um bom esforço dos discentes em realizar uma transposição didática mais eficiente.

Em relação a terceira orientação: As implicações para a alfabetização científica e o ensino de ciências, podem ser analisadas a partir das questões postas nos casos. Para realizar esta análise toma-se como base os três eixos da alfabetização científica de Sasseron et al (2013). No caso “A radiação do corpo negro" verifica-se um número grande de questões, algumas delas mal formuladas, pois acabam dando margem para os alunos responderem sim ou não. Além disso, as questões referentes ao conteúdo científico, muitas delas repetem a mesma explicação.

No que se refere as questões relacionadas a natureza da ciência, estas também se apresentam mal formuladas, podendo ocasionar confusão nas respostas dos estudantes. Em relação as questões formuladas no segundo caso, sobre o efeito fotoelétrico, estas se mostraram instigantes aos estudantes no que se refere tanto as questões conceituais, quanto relacionadas a natureza da ciência.

Já as implicações da ciência, tecnologia, sociedade e meio ambiente, precisavam ser melhor tratadas, a fim de trazer as relações entre elas. Para desenvolver um trabalho que efetivamente se propõe a relacionar os conhecimentos científicos com questões relacionadas à ciência, tecnologia e sociedade, é de extrema importância abordar de maneira explícita temas cotidianos (PINHEIRO, N. et. al., 2007) No terceiro caso, sobre a natureza da luz, as questões formuladas buscam discutir os três aspectos da alfabetização científica, de uma forma instigante aos alunos. São trabalhados tanto questões científicas, quanto a natureza da ciência e também as implicações do desenvolvimento científico na sociedade.

Analisando um pouco mais detalhadamente pode-se perceber em todos os textos, a despeito das suas características diferentes, que os mesmos apresentam uma organização similar. De acordo com Silva e Fossá (2015) a sistematização dos processos que envolvem a análise de conteúdo passam por uma leitura flutuante, seguida da seleção dos textos, formulação de hipóteses e, finalmente, elaboração dos indicadores. Utilizando-se dessa premissa percebemos que os textos possuem introduções similares, todas apresentando um contexto histórico pertinente ao tema a ser discutido. Essa característica, em particular, pode estar relacionada ao êxito na compreensão dos discentes da importância de se contextualizar o conhecimento científico.

Outro aspecto de uniformidade no conteúdo dos textos pode ser destacado ao realizarmos uma categorização dos termos utilizados nas perguntas. De acordo com Bardin (2004) as informações podem ser categorizadas, e agrupadas em núcleos de significados 
comuns, com a finalidade de oferecer análises mais assertivas sobre o conteúdo dos dados levantados. Se utilizarmos como categoria de análise os "termos que se referenciam diretamente ao leitor", por exemplo, encontramos elementos presentes nos três textos:

"Qual cor de camiseta você prefere usar no verão" (Texto 1)

"Seria você capaz de inventar uma explicação para o efeito fotoelétrico?" (Texto 2)

"[..] a que você atribui a inconsistência das explicações científicas?" (Texto 3)

Através desses exemplos percebemos que os discentes realizaram textualmente uma tentativa de aproximar o leitor (supostamente seus próprios alunos) do evento narrado no texto. $\mathrm{O}$ fato de que os grupos agiram de forma independente e sem se influenciarem, associado ao fato de que não foi solicitado previamente a utilização de tal linguagem, pode sugerir que a ideia de incluir o aluno como protagonista no processo de ensino é compartilhada no grupo trabalhado.

Outro exemplo positivo, já citado anteriormente, de que os discentes deram importância à discussão sobre a natureza da ciência, está no fato de que, em todos os textos, estão presentes elementos culturais e/ou econômicos, colocados deliberadamente relacionados aos estudos científicos. O aspecto consensual, que trata a ciência como um constructo social e humano, está presente de forma nos três textos. De uma forma geral a análise dos três textos nos permite afirmar que os elementos sobre filosofia, história e natureza da ciência, que foram abordados durante as atividades da disciplina, vieram à tona de várias maneiras.

As Figuras 4, 5 e 6 mostram as sequências didáticas elaboradas pelos discentes. Essas sequências foram elaboradas de forma que dariam sequência à proposta de estudo de caso histórico do texto inicial, inclusive foram elaboradas pelos mesmos grupos. $\mathrm{Na}$ análise das sequências didáticas busca-se investigarse estas propõem trabalhar os três eixos da alfabetização científica conforme orienta Sasseron et al (2013). 
Figura 4: Sequência didática sobre radiação de corpo negro.

\begin{tabular}{|c|c|c|c|}
\hline $\begin{array}{l}\text { Aula/ } \\
\text { Tempo }\end{array}$ & Conteúdos & Atividades realizadas & Objetivos \\
\hline $1 \mathrm{a} / 50 \mathrm{~min}$ & $\begin{array}{l}\text { Radiações do corpo } \\
\text { negro - FMC }\end{array}$ & $\begin{array}{l}\text { Leitura do estudo de caso e } \\
\text { resolução das questões. }\end{array}$ & $\begin{array}{l}\text { Investigar os conhecimentos prévios } \\
\text { dos alunos;(Ndc: O raciocinio } \\
\text { cientifico não se estabelece sem } \\
\text { apelar para fontes sociais, } \\
\text { espirituais, morais e sociais) }\end{array}$ \\
\hline $1 \mathrm{a} / 50 \mathrm{~min}$ & $\begin{array}{l}\text { Radiações do corpo } \\
\text { negro - FMC }\end{array}$ & Discussão do estudo de caso & $\begin{array}{l}\text { Discutir as respostas do estudo de } \\
\text { caso; }\end{array}$ \\
\hline $1 \mathrm{a} / 50 \mathrm{~min}$ & $\begin{array}{l}\text { Radiação } \\
\text { Infravermelha }\end{array}$ & Discussão e Experimento. & $\begin{array}{lcc}\text { Comprovar } & \text { experimentalmente } & \text { a } \\
\text { existência } & \text { da } & \text { radiação } \\
\text { infravermelha } & & \end{array}$ \\
\hline $2 a / 50 \mathrm{~min}$ & $\begin{array}{l}\text { Ondas } \\
\text { Eletromagnéticas } \\
\text { Radiação do Corpo } \\
\text { Negro. }\end{array}$ & $\begin{array}{l}\text { Aula expositiva e dialogada. Vídeo } \\
\text { sobre Radiação do Copo Negro } \\
\text { (https://youtu.be/pL3Zg-MYRMA). }\end{array}$ & Introduzir o conhecimento científico; \\
\hline $1 \mathrm{a} / 50 \mathrm{~min}$ & $\begin{array}{l}\text { Radiação } \\
\text { Infravermelha }\end{array}$ & Discussão e Experimento. & $\begin{array}{lcc}\text { Comprovar } & \text { experimentalmente } & \text { a } \\
\text { existência } & \text { da } & \text { radiação } \\
\text { infravermelha. } & & \\
\end{array}$ \\
\hline $2 \mathrm{a} / 50 \mathrm{~min}$ & $\begin{array}{l}\text { Catástrofe } \\
\text { Ultravioleta }\end{array}$ & $\begin{array}{l}\text { Leitura } \\
\text { (https://institutodepesquisascientific } \\
\text { as.wordpress.com/2016/04/17/o- } \\
\text { problema-da-radiacao-de-corpo- } \\
\text { negro-da-catastrofe-do-ultravioleta- } \\
\text { a-teoria-quantica/) e discussão. }\end{array}$ & $\begin{array}{l}\text { Relatar a evolução histórica do } \\
\text { fenômeno da emissão da radiação } \\
\text { do corpo negro; } \\
\text { (Ndc: A ciência é dinâmica, } \\
\text { mutável e experimental) }\end{array}$ \\
\hline $2 a / 50 \min$ & $\begin{array}{ll}\text { Fatos históricos } & \text { da } \\
\text { Física Clássica } & \\
\text { Catástrofe } & \text { do } \\
\text { Ultravioleta; } & \\
\text { Fatos históricos da } \\
\text { Física Quântica }\end{array}$ & Trabalho em grupo & $\begin{array}{l}\text { Diferenciar, por meio de exempli- } \\
\text { ficacões, a teoria clássica da teoria } \\
\text { contemporânea para a radiação do } \\
\text { corpo negro. } \\
\text { Refletir sobre as implicações da } \\
\text { natureza da ciência na sociedade. }\end{array}$ \\
\hline $2 \mathrm{a} / 50 \mathrm{~min}$ & $\begin{array}{l}\text { Fatos históricos da } \\
\text { Física Clássica } \\
\text { Fatos históricos da } \\
\text { Física Quântica. }\end{array}$ & $\begin{array}{l}\text { Mapas } \quad \text { conceituais } \\
\text { (https://www.youtube.com/watch?v } \\
=\text { F54SWctP7-E); }\end{array}$ & $\begin{array}{l}\text { Avaliar os conhecimentos } \\
\text { adquiridos durante a sequência. }\end{array}$ \\
\hline
\end{tabular}

Fonte: Produção própria

Na sequência didática sobre a radiação do corpo negro, o grupo utilizou os três momentos pedagógicos. É interessante ressaltar que no momento da organização do conhecimento os discentes trazem diversas atividades com características, o grupo buscou usar diferentes recursos didáticos, como vídeos, experimentos e trabalhos em grupos, o que concorda com as orientações de Delizoicov e Angotti (1990).

Em relação à aplicação do conhecimento, momento no qual são feitas as relações entre os temas da problematização e os conhecimentos adquiridos na organização do conhecimento, vale ressaltar que o grupo propôs uma alternativa eficiente, que é o trabalho com mapas conceituais, pois o mapa conceitual é uma estratégia facilitadora na tarefa de aprender a aprender (TAVARES, 2007, p.81).

No que se refere aos eixos da alfabetização científica, o primeiro eixo, sobre a aprendizagem de conceitos, pode-se perceber que o grupo apresentou bastante preocupação com isto, pois buscou explorar desde as percepções sobre este conceito contrapondo teoria clássica e moderna e também por meio de experimentos. No que se refere a natureza da ciência, 
segundo eixo, o grupo buscou trabalhar com alguns aspectos consensuais. Já em relação ao terceiro eixo, este não foi percebido tão claramente em atividades a serem realizadas durante a sequência didática.

Figura 5: Sequência didática sobre o efeito fotoelétrico

\begin{tabular}{|c|c|c|c|}
\hline Semanas & $\begin{array}{c}\text { Momento } \\
\text { pedagógico }\end{array}$ & Atividades sugeridas & Objetivos \\
\hline $1^{a}$ e $2^{a}$ & $\mathrm{P}$ & $\begin{array}{l}\text { Dividir a turma em equipes e apresentar a } \\
\text { sequência de trabalho. } \\
\text { Apresentar aos alunos fotos de } \\
\text { aplicações do efeito fotoelétrico dos dias } \\
\text { atuais e fotos dos cientistas e dos } \\
\text { experimentos que contribuíram para } \\
\text { descoberta desse efeito. } \\
\text { Pedir aos alunos para associar as fotos e } \\
\text { refletir o que pode haver em comum entre } \\
\text { elas. Apresentar o estudo de caso. }\end{array}$ & $\begin{array}{l}\text { Resgatar } \\
\text { conhecimento prévio. } \\
\text { Proporcionar os alunos o } \\
\text { desenvolvimento dos } \\
\text { aspectos da natureza da } \\
\text { ciência. }\end{array}$ \\
\hline \multirow[b]{2}{*}{$\begin{array}{c}3^{\circ}, 4^{\circ} \mathrm{e} \\
5^{\circ}\end{array}$} & \multirow[b]{2}{*}{$\mathrm{O}$} & $\begin{array}{l}\text { Apresentação do conteúdo a partir do } \\
\text { estudo de caso (efeito fotoelétrico) } \\
\text { Pedir que os alunos observem e realizem } \\
\text { experimentos através de um roteiro. }\end{array}$ & \multirow{2}{*}{$\begin{array}{l}\text { Proporcionar os alunos o } \\
\text { desenvolvimento das } \\
\text { habilidades efoito } \\
\text { competências sobre o } \\
\text { conceito do efeitro. } \\
\text { fotoelétrico. } \\
\text { Proporcionar os alunos o } \\
\text { desenvolvimento dos } \\
\text { aspectos da natureza da } \\
\text { ciência. }\end{array}$} \\
\hline & & $\begin{array}{l}\text { Pedir os alunos que relacionem as etapas } \\
\text { realizadas por eles no experimento com a } \\
\text { trajetória descrita no estudo de caso }\end{array}$ & \\
\hline \multirow[b]{3}{*}{$6^{\circ}$} & \multirow[b]{3}{*}{ A } & Resolução de uma lista de exercícios. & \multirow{3}{*}{$\begin{array}{l}\text { Verificar através do } \\
\text { estudo de caso se o } \\
\text { significado que o aluno } \\
\text { captou é aceito e } \\
\text { compartilhado } \\
\text { socialmente. }\end{array}$} \\
\hline & & Aplicação novamente do estudo de caso. & \\
\hline & & $\begin{array}{l}\text { Apresentação das equipes comparando } \\
\text { as respostas dos questionamentos } \\
\text { presente no estudo de caso. }\end{array}$ & \\
\hline
\end{tabular}

Fonte: Produção própria

A sequência didática apresentada pelo segundo grupo, a respeito do efeito fotoelétrico, foi estruturada em torno dos três momentos pedagógicos propostos por Delizoicov e Angotti (1990). Utilizaram como recursos didáticos o uso de experimentos, lista de exercícios e trabalhos em grupo. Pode-se perceber que este grupo preocupou-se mais com o primeiro eixo da alfabetização científica destacado por Sasseron, a aprendizagem de conceitos científicos. A natureza da ciência, segundo eixo, parece ser explorada mais no momento de discussão das questões do caso. Já em relação ao terceiro eixo, implicações da ciência, tecnologia, sociedade e ambiente, não se percebe a discussão destas relações, são apenas explorados aplicações no cotidiano, mas não aparece na sequência didática as implicações destas aplicações tecnológicas na sociedade. 
Figura 6: Sequência didática sobre o efeito fotoelétrico

\begin{tabular}{|c|c|c|c|}
\hline Aulas & Conteúdos & $\begin{array}{c}\text { Atividades realizadas } \\
\end{array}$ & Objetivos \\
\hline $\begin{array}{l}\text { Aula } 1- \\
01 \mathrm{~h} \text { e } 40 \\
\text { minutos }\end{array}$ & $\begin{array}{l}\text { Importância do } \\
\text { progresso } \\
\text { histórico do } \\
\text { conhecimento } \\
\text { da natureza da } \\
\text { luz; }\end{array}$ & $\begin{array}{l}\text { Realizar a leitura do estudo de caso e } \\
\text { em seguida solicitar a elaboração das } \\
\text { respostas expondo suas ideias iniciais; } \\
\text { Discussão geral da aplicabilidade da } \\
\text { luz na sociedade (visão, tratamentos } \\
\text { de saúde com radiações, telescópio, } \\
\text { microscópio eletrônico etc.) }\end{array}$ & $\begin{array}{l}\text { NdC: O desacordo entre os } \\
\text { cientistas sempre é } \\
\text { possível; 3) A ciência é } \\
\text { dinâmica, mutável e } \\
\text { experimenta. } \\
\text { Colher as concepções } \\
\text { prévias dos alunos quanto } \\
\text { à construção histórica do } \\
\text { conhecimento científico. }\end{array}$ \\
\hline $\begin{array}{l}\text { Aula 2- } \\
50 \\
\text { minutos }\end{array}$ & $\begin{array}{l}\text { Características } \\
\text { corpusculares } \\
\text { da luz }\end{array}$ & $\begin{array}{l}\text { Utilizar a plataforma Phet para } \\
\text { demonstração do desvio da luz- um } \\
\text { comportamento corpuscular em linhas } \\
\text { retas, conforme proposto por Newton- } \\
\text { (https://phet.colorado.edu/sims/html/be } \\
\text { nding-light/latest/bending- } \\
\text { light_pt_BR.html) } \\
\text { Utilizar uma imagem de realidade } \\
\text { aumentada do globo ocular humano }\end{array}$ & $\begin{array}{l}\text { Compreender que a luz se } \\
\text { comporta como partícula } \\
\text { quando analisadas sob } \\
\text { condições especiais } \\
\begin{array}{l}\text { Demonstrar e discutir o } \\
\text { comportamento } \\
\text { corpuscular da luz na } \\
\text { visão. }\end{array}\end{array}$ \\
\hline $\begin{array}{l}\text { Aula 3- } \\
50 \\
\text { minutos }\end{array}$ & $\begin{array}{l}\text { Características } \\
\text { ondulatórias } \\
\text { da luz }\end{array}$ & 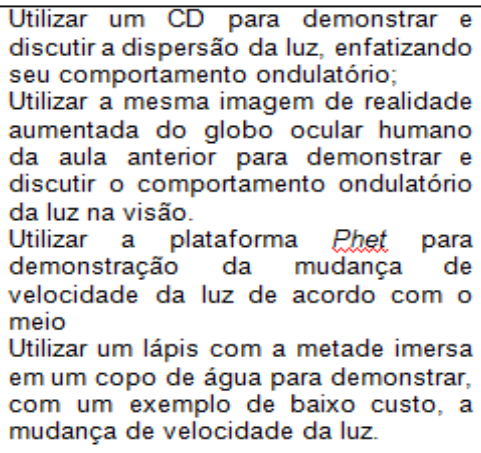 & $\begin{array}{l}\text { Compreender que a luz se } \\
\text { comporta como onda } \\
\text { quando analisadas sob } \\
\text { condições especiais; } \\
\text { Compreender que a luz } \\
\text { branca é uma radiação do } \\
\text { espectro eletromanético } \\
\text { composta por todas as } \\
\text { radiações conhecidas (do } \\
\text { vermelho ao violeta) } \\
\text { Compreender a mudança } \\
\text { de velocidade da luz de } \\
\text { acordo com o meio. }\end{array}$ \\
\hline $\begin{array}{l}\text { Aula 4- } \\
50 \\
\text { minutos }\end{array}$ & $\begin{array}{l}\text { Dualidade } \\
\text { onda-partícula } \\
\text { da luz }\end{array}$ & $\begin{array}{l}\text { O Phet, para demonstrar o efeito } \\
\text { fotoelétrico- } \\
\text { (https://phet.colorado.edu/pt_BR/simul } \\
\text { ation/legacy/photoelectric); } \\
\text { Utilizar o Phet para demonstrar o } \\
\text { experimento de interferência quântica } \\
\text { baseado no caráter ondulatório do } \\
\text { elétron proposto por De Broglie } \\
\text { (https://phet.colorado.edu/pt_BR/simul } \\
\text { ation/legacy/quantum-wave- } \\
\text { interference) }\end{array}$ & $\begin{array}{l}\text { Compreender } \\
\text { comportamento dual da luz: } \\
\text { onda-partícula } \\
\text { Compreender e efetuar } \\
\text { cálculos a aplicando a } \\
\text { equação de De Broglie (m } \\
V=h / \lambda \text { ) }\end{array}$ \\
\hline $\begin{array}{l}\text { Aula 5- } \\
50 \\
\text { minutos }\end{array}$ & $\begin{array}{l}\text { Dualidade } \\
\text { onda-partícula } \\
\text { da luz }\end{array}$ & Retomar o estudo de caso & $\begin{array}{l}\text { Verificar como o aluno } \\
\text { compreendeu a construção } \\
\text { histórica do conhecimento } \\
\text { científico em torno da } \\
\text { natureza da luz e sua } \\
\begin{array}{l}\text { aplicabilidade } \\
\text { sociedade. }\end{array} \\
\end{array}$ \\
\hline
\end{tabular}

Fonte: Produção própria

Na sequência didática acerca da natureza da luz, foi utilizado os 3 passos de Linhares e Reis (2008) para o trabalho com o estudo de caso histórico. Os 3 passos foram organizados corretamente de acordo com o referencial adotado, trazendo o caso no primeiro e terceiro passo. Enquanto no segundo passo é trabalhado o tema de estudo.

O grupo utilizou-se de experimento e uso de tecnologias a partir da plataforma phet. Em relação aos três eixos da alfabetização científica, pode-se observar que o primeiro eixo, aprendizagem de conceitos científicos foi bastante explorado, tanto por meio de experimentos, quanto pelo uso da tecnologia. No que se refere ao segundo eixo da natureza da ciência, 
verifica-se que este ficou restrito a discussão as questões do caso. Enquanto o terceiro eixo, não foi explorado.

Pode-se perceber que, nas três sequências didáticas, novamente tem-se alguns pontos de convergência. Embora elas tenham apresentado uma grande variedade de atividades distintas, é notório a presença de elementos tecnológicos nas três. Desde vídeos até plataforma de simulação (Phet), as três propostas buscaram relacionar elementos cotidianos e tecnológicos com a finalidade de fornecer mais subsídios ao processo de aprendizagem. De forma análoga uma postura sempre presente nessas propostas é a inclusão do aluno de uma forma ativa, seja por meio de debates ou de experimentos.

Um dos principais pontos no que diz respeito à ideia central da alfabetização científica, foi também uma constante nas propostas dos discentes. Isso ocorreu pois em todos os textos houve, de certa forma, uma tentativa explícita de relacionar conhecimentos científicos com suas respectivas aplicações cotidianas, em várias atividades propostas os discentes buscaram se inspirar em situações cotidianas para ressignificar os conteúdos.

\section{Considerações Finais}

Neste artigo foi apresentada uma proposta para trabalhar com a filosofia, história e natureza da ciência no ensino de ciências, em particular de física. Além disso, foi trabalhado uma metodologia ativa, o método de estudo de caso para organizar uma sequência didática com a utilização da história da ciência no ensino. A proposta foi desenvolvida em uma turma de 10 alunos do MNPEF.

Durante a realização da proposta os discentes tiveram a oportunidade de discutir sobre a filosofia, história e natureza da ciência, além de poderem fazer atividades que visava facilitar o aprendizado do que se estava discutindo.

Uma das atividades propostas, investigadas no presente artigo, foi a elaboração de um estudo de caso histórico e se uma sequência didática.

A análise dos casos históricos construídos, tomou como base as orientações de Stinner (2003), e foi possível perceber que os casos elaborados, no geral estavam bem estruturados. Em relação ao contexto histórico, experimentos e ideias principais e alfabetização científica.

A análise das sequências didáticas tomou como base os 3 eixos da alfabetização científica proposta por Sasseron et AL (2013). Foi possível perceber que as sequências didáticas elaboradas preocuparam-se mais com o primeiro eixo a aprendizagem de conceitos científicos, destinando diferentes recursos didáticos para este fim. Em relação ao segundo eixo, a natureza da ciência, foi possível perceber que este seria mais explorado no momento de discussão do estudo de caso histórico. Já no que se refere ao terceiro eixo, implicações da ciência, tecnologia, sociedade e ambiente, pouco foi explorado nas sequências, em algumas poderia se notar ISSN 2526-2882 
apenas a tentativa de mostrar a aplicação tecnológica daquele princípio do cotidiano dos alunos, mas não fazia uma alusão a discutir mais aprofundadamente.

No entanto, considera-se que os resultados foram positivos, pois conseguiu-se que os discentes, professores em exercício, saíssem de sua zona de conforto e identificassem meios de não apenas explicar conteúdos, mas também mostrar como estes foram construídos e incorporar a história da ciência em sua elaboração de aulas.

A partir do trabalho realizado, almeja-se que esta proposta possa ser realizada em outros contextos com outros professores, seja em formação inicial ou continuada, a fim de fazêlos refletir sobre o processo de construção do conhecimento científico e também pensar sobre sua própria prática, incorporando a história e natureza da ciência no ensino e também o uso de metodologias de ensino que possam fazer o aluno ativo em suas aulas.

\section{Referências}

ACEVEDO, J. A. et. al. Mitos da didática das ciências acerca dos motivos para incluir a natureza da ciência no ensino das ciências. Ciência \& Educação, v. 11, n. 1, p. 1-15, 2005.

BARDIN, L. Análise de conteúdo. 3. ed. Lisboa: Edições 70, 2004.

BERBEL, N. As metodologias ativas e a promoção da autonomia dos estudantes. Semina, Londrina, 32 (1), 25-40, (2011).

DELIZOICOV, D. \& ANGOTTI, J. A. (1990). Física. São Paulo: Cortez.

FORATO, T. C. M. A natureza da ciência como saber escolar: um estudo de caso a partir da história da luz. Tese de Doutorado em Educação. USP, São Paulo, 2009. v. 1, 204 p.

HERREID, C.F. Casestudies in science-a novel methodofscienceeducation. Journal of College Science Teaching, 23, 4, 221-229, 1994.

LINHARES, M.P. e E.M. Reis. Estudos de caso como estratégia de ensino na formação de professores de física. Ciência \& Educação, 14, 3, 55- 74, 2008.

MATTHEWS, M. R. História, filosofia e ensino de ciências: a tendência atual de reaproximação. Caderno Catarinense de Ensino de Física, v. 12, n. 3, p. 164214, Florianópolis, 1995.

MCCOMAS, W. F., Almazroa, H.; Clough, M. The Natureof Science in Science Education: Anintroduction. Science \&Education. v. 7, p. 511-532. 1998.

MENDES, G. H. G. I.; BATISTA, I. L. Matematização e ensino de Física: uma discussão de noções docentes. Ciência \& Educação., Bauru, v. 22, n. 3, p. 757-771, 2016

MOURA, B.A., O que é natureza da Ciência e qual sua relação com a História e Filosofia da Ciência? Revista Brasileira de História da Ciência, Rio de Janeiro, v. 7, n. 1, p. 32-46, 2014.

ISSN 2526-2882 
PÉREZ, Daniel Gil. MONTORO, Isabel Fernández. ALÍS, Jaime Carrascosa. CACHAPUZ, António. PRAIA, João. Para uma visão não deformada do trabalho científico. Ciência e Educação, v.7, n.2, p.125-153, 2001.

POZO, J.I.; CRESPO, M.A.G.A Aprendizagem e o Ensino de Ciências: do Conhecimento Cotidiano ao Conhecimento Científico. 5.ed. Porto Alegre: Artmed, 2009

PINHEIRO, Nilcéia A. M.; SILVEIRA, Rosemari M. C. F.; BAZZO, Walter A. Ciência, Tecnologia e Sociedade: a relevância do enfoque CTS para o contexto do Ensino Médio. Ciênc. educ. (Bauru), Bauru, v. 13, n. 1, p. 71-84, Apr. 2007. Disponível em:<http://www.scielo.br/scielo.php?script=sci_arttext\&pid=S1516$73132007000100005 \& \operatorname{lng}=\mathrm{en} \& \mathrm{nrm}=\mathrm{iso}>$. Acesso em 27/02/2019.

PRAIA, J.; GIL-PÉREZ, D.; VILCHES, A. O papel da natureza da ciência na educação para a cidadania. Ciência\&Educação, v. 13, n. 2, p. 141-156, 2007.

SÁ, L. P.; QUEIROZ, S. L. Estudo de Casos no Ensino de Química. Campinas: Ed. Átomo, 2009. SASSERRON. L.; BRICCIA.; V.; CARVALHO, A. Aspectos da natureza da ciência em sala de aula: exemplos do uso de textos científicos em prol do processo de alfabetização científica dos estudantes In: SILVA, C.C.; PRESTES, M. E (orgs). Aprendendo ciência e sobre sua natureza: abordagens históricas e filosóficas. 1 ed. São Carlos, SP: Tipografia Editora, p.265-276, 2013.

SILVA, A. H.; FOSSÁ, M. I. T. Análise de conteúdo: exemplo de aplicação da técnica para a análise de dados qualitativos. Qualit@s Revista Eletrônica, n. 1, v. 17, 2015. p. 3.

STINNER, A.; McMillan, B.; Don Metz; Jilek, J. e S. Klassen. The Renewalof Case Studies in Science Education. Science \&Education (Dordrecht), 12, 7, 617-643, 2003.

TAVARES, Romero. Aprendizagem Significativa. Disponível em: http://www.fisica.ufpb.br/ romero/pdf/2004AprendizagemSignificativaConceitos. pdf. Acesso em Fevereiro de 2019.

VILLANI, A.; PACCA, J. L. A.; FREITAS, D. Science teachereducation in Brazil: 1950- 2000. Science\&Education, v. 18, p. 125-148, 2009.

\section{Biografia Resumida}

Cassiana Barreto Hygino Machado: Doutora em Ciências Naturais, com ênfase no Ensino de Ciências pela Universidade Estadual do Norte Fluminense Darcy Ribeiro - UENF (2015) e Mestra em Ciências Naturais, com ênfase no Ensino de Ciências pela Universidade Estadual do Norte Fluminense Darcy Ribeiro - UENF (2011). Possui ISSN 2526-2882 
Graduação em Licenciatura em Física pela Universidade Estadual do Norte Fluminense Darcy Ribeiro - UENF (2008) Atualmente é professora do Instituto Federal de Educação Ciência e Tecnologia Fluminense - Campus Cambuci e professora do Mestrado Nacional Profissional em Ensino de Física (MNPEF) - pólo IFF

Contato: cassiana.h.machado@iff.edu.br

Link Lattes: http://Link Lattes.cnpq.br/8140578621545833

Tiago Destéffani Admiral: Licenciado em Física pela Universidade Federal de Viçosa (2008). Especialista em Educação Profissional pelo Instituto Federal do Espírito Santo - IFES (2010). Mestre na área de Ensino de Ciências e Matemática - IFES (2013). Doutorado em Ciências Naturais - UENF (2018). Tem experiência em ensino de Física, Cálculo Diferencial e Integral e Equações Diferenciais Ordinárias. Atualmente é professor de física efetivo do Instituto Federal Fluminense - IFF - RJ. Atua nos cursos integrados ao ensino médio, no curso de Licenciatura em Matemática e no programa de mestrado MNPEF. Desenvolve projetos de pesquisa na área de tecnologias no Ensino de Física, com ênfase na aplicação de controladores lógico programáveis como ferramenta de ensino.

Link Lattes: http://Link Lattes.cnpq.br/6811361479513782

e-mail: tdesteffani@gmail.com

Renata Lacerda Caldas: Possui graduação em Licenciatura Em Física pela Universidade de Brasília (1997), Mestrado em Ensino de Ciências pela Universidade de Brasília (2007) e doutorado em Ciências Naturais pela Universidade Estadual do Norte Fluminense Darcy Ribeiro (2011). Atualmente é professora efetiva do Instituto Federal Fluminense (IFF). Tem experiência na área de Física Geral, com ênfase em Ensino de Física, atuando principalmente nos seguintes temas: utilização de estratégias de ensino e avaliação da aprendizagem, aprendizagem significativa em física, interdisciplinaridade em ciências naturais, formação de professores. Atualmente coordena a área de Ciências da Natureza no Laboratório Interdisciplinar de Formação de Educadores (LIFE) e o Subprojeto de Física do Programa Institucional de Bolsa de Iniciação à Docência (PIBID), ambos no IFF. Desde 2014,2 coordena o 
polo 34/IF Fluminense do Mestrado Nacional Profissional em Ensino de Física (MNPEF) da SBF/CAPES.

Link Lattes: http://Link Lattes.cnpq.br/o326014908040698

e-mail: renata.caldas@iff.edu.br 